\title{
Two mutations preventing PDZ-protein interactions of GluR1 have opposite effects on synaptic plasticity
}

\author{
Jannic Boehm, ${ }^{1,3}$ Ingrid Ehrlich, ${ }^{1,3}$ Helen Hsieh, ${ }^{1,2,3}$ and Roberto Malinow ${ }^{1,2,4}$ \\ ${ }^{1}$ Cold Spring Harbor Laboratory, Cold Spring Harbor, New York 11724, USA; ${ }^{2}$ Department of Neurobiology and Behavior, SUNY \\ Stony Brook, Stony Brook, New York 11794, USA
}

\begin{abstract}
The regulated trafficking of GluR1 contributes significantly to synaptic plasticity, but studies addressing the function of the GluRI C-terminal PDZ-ligand domain in this process have produced conflicting results. Here, we resolve this conflict by showing that apparently similar C-terminal mutations of the GluR1 PDZ-ligand domain result in opposite physiological phenotypes during activity- and CamKIl-induced synaptic plasticity.
\end{abstract}

The modification of synapses is a key feature underlying plasticity that occurs during development and learning. Mechanistic studies have shown that synaptic incorporation of additional AMPA-type receptors (AMPA-Rs) contributes to activity-induced enhancement at glutamatergic synapses during long-term potentiation (LTP) and plasticity in vivo (Malinow and Malenka 2002; Bredt and Nicoll 2003; Takahashi et al. 2003; Rumpel et al. 2005). However, a clear understanding of the molecular interactions that lead to stable synaptic incorporation of AMPA-Rs is missing.

Here, we investigate the role played by the last seven amino acids in the GluR1 C terminus, which ends in a PDZ type I consensus sequence (S/T-X- $\phi$ ) (Songyang et al. 1997). PDZ domains play critical roles in protein-protein interactions for many cellular processes (Garner et al. 2000; Kim and Sheng 2004). The GluR1 C-terminal PDZ-ligand domain is conserved among humans (TGL), rodents (TGL), birds (TGL), fish (SGM), and worms (TLF), suggesting that this region is important for GluR1 function (Chang and Rongo 2005). Early studies showed that a point mutation in this PDZ-ligand of GluR1 (GluR1T887A) blocked interactions with PDZ proteins (Cai et al. 2002) and prevented longterm potentiation (LTP) and CaMKII-induced potentiation in organotypic hippocampal slices (Hayashi et al. 2000). Subsequent studies with this GluR1 (T887A) mutant in dissociated cultured neurons (Passafaro et al. 2001), hippocampal slice cultures (Piccini and Malinow 2002), or Caenorhabditis elegans in vivo (Chang and Rongo 2005) also found receptor trafficking deficits. In contrast, a recent study using a mouse knock-in model showed that removal of the last seven amino acids of GluR1 (GluR1 $\Delta 7$ ) does not affect receptor incorporation into synapses or LTP (Kim et al. 2005). Although both mutations, T887A and $\Delta 7$, prevent interactions between the GluR1 cytoplasmic tail and PDZ proteins (Cai et al. 2002; Kim et al. 2005), they appear to have opposite effects on synaptic receptor incorporation and plasticity. It is unclear if these results are due to experimental approaches, or if a mechanistic difference exists between the point mutant (GluR1[T887A]) and the deletion mutant (GluR1 $\Delta 7$ ).

To resolve this discrepancy, we compared the physiological effects of GluR1(wildtype[wt]), GluR1(T887A), and GluR1 $\Delta 7$ in the same experimental system, using viral overexpression (Sindbis virus, Invitrogen) of recombinant receptors in organotypic slice cultures. To visualize neurons that express receptors, we tagged GluR1 and its mutants with GFP. GFP-GluR1(wt) and GFP-

\footnotetext{
${ }^{3}$ These authors contributed equally to this work. ${ }^{4}$ Corresponding author.

E-mail malinow@cshl.edu; fax (516) 367-8372.

Article published online before print. Article and publication date are at http:// www.learnmem.org/cgi/doi/10.1101/lm.253506.
}

GluR1(T887A), with or without coexpressing tCaMKII (using an internal ribosomal entry site), were made as previously described (Shi et al. 1999; Hayashi et al. 2000). Similarly, GFP-GluR1 4 , generated by deleting the coding sequence for the last seven Cterminal amino acids (Kim et al. 2005), was expressed alone or together with tCamKII. Organotypic hippocampal slice cultures were prepared from 6- to 7-d-old rat pups (Stoppini et al. 1991) and infected with Sindbis virus after 7-9 d in vitro as previously described (Shi et al. 1999). Expression of recombinant receptors was allowed for $12-36 \mathrm{~h}$, and infected neurons were identified under epifluorescence. To determine physiological effects of the GluR1 constructs, we recorded simultaneously from neighboring control (uninfected) and infected CA1 pyramidal neurons, and monitored Schaffer collateral-evoked excitatory postsynaptic currents (EPSCs) in the presence of $100 \mu \mathrm{M}$ picrotoxin as previously described (Zhu et al. 2000). Only neuron pairs with input and series resistance within $25 \%$ of each other were analyzed. Stimulus intensity was adjusted so that one neuron in a pair had an average AMPA-EPSC amplitude of $\sim 30 \mathrm{pA}$. To prevent bursting activity, the artificial cerebrospinal fluid (ACSF) was modified to contain $4 \mathrm{mM} \mathrm{Ca}^{2+}$ and $4 \mathrm{mM} \mathrm{Mg}^{2+}$, and $1 \mu \mathrm{M}$ (for LTP) or $4 \mu \mathrm{M}$ (for all other experiments) 2-Chloroadenosine. In addition, cuts were made at the border between the CA1 and the CA3. The internal solution for patch recordings was cesium-methanesulfonate-based (Zhu et al. 2000) with low concentrations of $\mathrm{Ca}^{2+}$ buffers to allow for LTP, and supplemented with $100 \mu \mathrm{M}$ spermine to allow for detection of rectifying receptors. When overexpressed, recombinant GFP-GluR1 forms predominantly homomeric and outwardly rectifying receptors, an electrophysiological property that allows us to measure their synaptic incorporation (Hayashi et al. 2000; Shi et al. 2001; Brown et al. 2005; Zhu et al. 2005). We calculated rectification as the ratio of peak synaptic AMPA-current measured at holding potentials of $-60 \mathrm{mV}$ and $+40 \mathrm{mV}$ (corrected for current at $0 \mathrm{mV}$ ) in the presence of $100 \mu \mathrm{M}$ D,L-APV to block NMDA components. Higher rectification values indicate a larger proportion of homomeric receptors at synapses. During all recordings, experimenters were blind as to which receptor construct was expressed, and each experiment was performed by at least two independent investigators. Using these techniques, we tested if and how the different PDZ mutations in GluR1 affect two forms of synaptic plasticity: LTP and potentiation by constitutively active CaMKII (Hayashi et al. 2000; Poncer et al. 2002).

We first assayed synaptic potentiation induced by coexpression of a truncated and constitutively active form of CaMKII (tCaMKII). About 12-18 h after viral delivery, we compared properties of AMPA-mediated EPSCs in pairs of neighboring CA1 pyramidal neurons, one infected and one control. In agreement 
with previous findings (Hayashi et al. 2000; Poncer et al. 2002), synaptic transmission was potentiated in neurons coexpressing tCaMKII and GluR1(wt). While the average EPSC was $39.3 \pm 2.9$ $\mathrm{pA}$ in control cells, it increased to $52.0 \pm 4.5 \mathrm{pA}$ in infected cells $(n=24$, Fig. 1A). As expected from earlier published results (Hayashi et al. 2000), we found that EPSCs were decreased by

A GluR1(wt) + tCaMKII

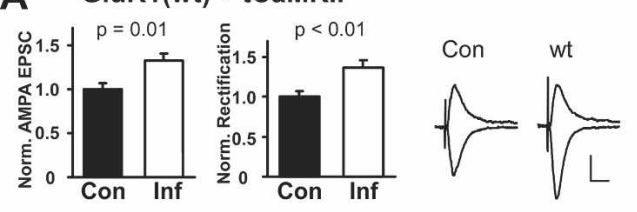

B GluR1(T887A) + tCaMKII

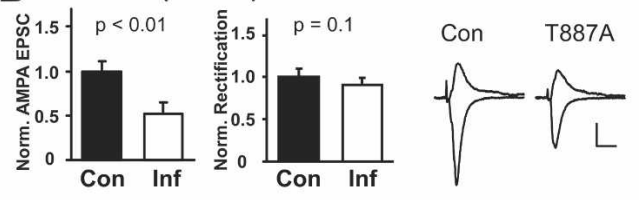

\section{GluR1 $\triangle 7+$ tCaMKII}
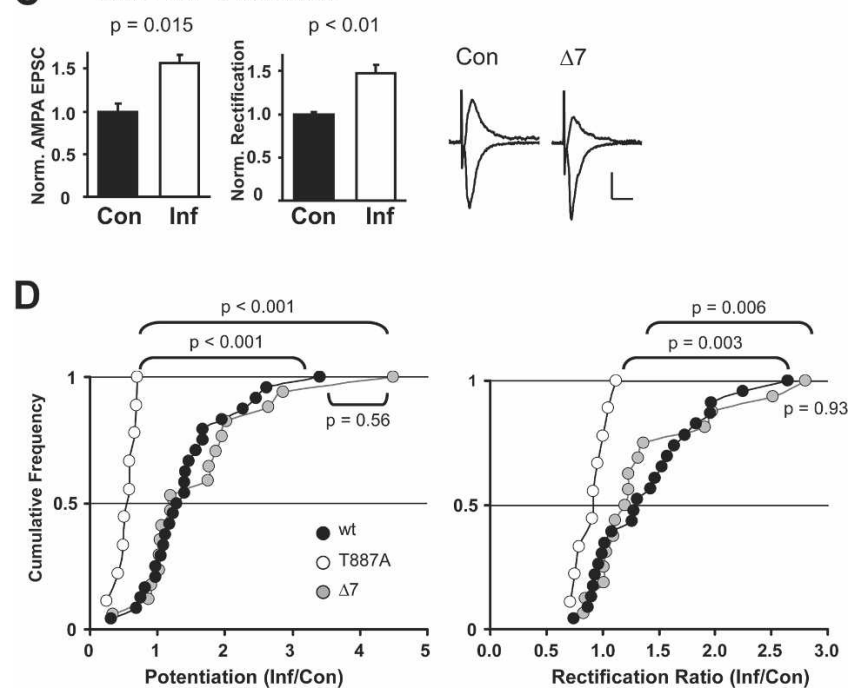

Figure 1. CaMKII-induced potentiation was blocked by coexpression with GluR1(T887A), but not by coexpression with GluR1 $\Delta 7$. $(A, B, C) \mathrm{Am}$ plitudes and rectification of AMPA-mediated EPSCs recorded in neighboring pairs of infected and control CA1 neurons to assess if coexpression of active CaMKII delivered GluR1 mutants to synapses. Amplitude and rectification values were normalized to that of control neurons. $(A)$ tCaMKII delivered GluR1(wt) to synapses. The EPSC amplitude increased from $1 \pm 0.07$ (control) to $1.32 \pm 0.09$ (infected; $n=24$ ), and rectification increased from $1 \pm 0.07$ (control) to $1.37 \pm 0.10$ (infected; $n=23$ ). (B) GluR1(T887A) blocked potentiation by tCaMKII. The EPSC amplitude decreased from $1 \pm 0.11$ (control) to $0.52 \pm 0.12$ (infected, $n=9$ ), and rectification was not changed $(1 \pm 0.10$, control to $0.90 \pm 0.10$, infected; $n=9$ ). (C) tCaMKII delivered GluR1 $\Delta 7$ to synapses. The EPSC amplitude increased from $1 \pm 0.09$ (control) to $1.56 \pm 0.10$ (infected, $n=17$ ), and rectification increased from $1 \pm 0.03$ (control) to $1.47 \pm 0.10$ (infected, $n=16$ ). P-values are shown for Wilcoxon tests. Traces are averages of $>50$ individual EPSCs recorded at $-60 \mathrm{mV}$ (inward current) and $+40 \mathrm{mV}$ (outward current) in the presence of APV. Scale bars: 20 pA, 20 msec. (D) Comparison of different GluR1 mutants. There was no change in the amount of tCaMKII-induced potentiation in the presence of GluR1 (wt) or GluR1 $\Delta 7$, while GluR1(T887A) was significantly different from both. There was also no difference in magnitude of rectification change with GluR1(wt) or GluR1 $\Delta 7$, while GluR1(T887A) rectification was significantly different from both. $(n)$ Number of cell pairs recorded. $P$-values shown for $t$-tests performed on log-normalized data. almost 50\% from $63.4 \pm 7.2 \mathrm{pA}$ in control cells to $33.1 \pm 4.0 \mathrm{pA}$ in neurons coexpressing tCaMKII and GluR1(T887A) $(n=9$, Fig. 1B). Interestingly, tCamKII also potentiated synaptic transmission when coexpressed with GluR1 $\Delta 7$, from $34.2 \pm 3.1 \mathrm{pA}$ in control cells to $53.4 \pm 5.3 \mathrm{pA}$ in infected cells ( $n=17$, Fig. 1C). Moreover, rectification, a measure of synaptic incorporation of recombinant GluR1 homomers, was enhanced in neurons coexpressing tCaMKII with GluR1(wt) $(1.85 \pm 0.12$ vs. $2.53 \pm 0.25$, control and infected, $n=23)$ or GluR $1 \Delta 7(1.73 \pm 0.04$ vs. $2.56 \pm 0.25$, control and infected, $n=16$ ), indicating that these receptors were delivered to synapses (Fig. 1A,C). In contrast, neurons coexpressing tCaMKII and GluR1(T887A) showed no change in rectification $(2.08 \pm 0.20$ vs. $1.88 \pm 0.18$, control and infected, $n=9$, Fig. 1B), indicating that they are not incorporated at synapses. Taken together, we find that GluR1(wt) and GluR1 $\Delta 7$ behaved the same during CaMKII-induced plasticity; both receptors allowed potentiation and were delivered to synapses at similar levels (Fig. 1D). In contrast, GluR1(T887A) behaved significantly different, since it blocked CaMKII-induced potentiation and was not delivered to synapses (Fig. 1D).

We asked if the three GluR1 constructs could simply be incorporated into synapses during basal levels of activity. We therefore expressed the receptors without tCamKII for 24-36 h to allow ample time for receptor trafficking to occur. None of the receptor constructs could be detected electrophysiologically at synapses when we compared rectification values between control and infected neurons (Fig. 2A,B,C); for GluR1(wt) $2.09 \pm 0.20$ vs. $2.08 \pm 0.14(n=10)$, for GluR1(T887A) $1.77 \pm 0.13$ vs. $1.87 \pm 0.07(n=9)$, and for GluR $1 \Delta 71.90 \pm 0.36$ vs. $1.91 \pm 0.25(n=7)$. While we did not detect a change in AMPAEPSC amplitude when expressing GluR1(wt) alone $(38.3 \pm 6.0$ vs. $44.3 \pm 5.9 \mathrm{pA}$, control vs. infected, $n=12$ ), we observed $25 \%$ decrease in AMPA-EPSCs after infection with GluR1(T887A) $(45.3 \pm 5.2$ vs. $33.2 \pm 3.7 \mathrm{pA}$, control vs. infected, $n=15)$ and with GluR1 $\Delta 7(43.1 \pm 4.0$ vs. $33.3 \pm 4.6 \mathrm{pA}$, control vs. infected, $n=15)$. The finding that expression of GluR1(T887A) depressed transmission in the presence and absence of tCaMKII suggests that it may interfere with tCaMKIIdriven delivery (consistent with previous findings by Hayashi et al. [2000]) as well as with spontaneous activity-induced delivery or replacement of receptors. The latter has not been previously observed (Hayashi et al. 2000), but may be due to differences in ages, expression time, and activity levels in our current cultures.

We next tested how the different GluR1 constructs affect LTP. To first rule out the possibility that effects on LTP may result from changes in NMDA-mediated transmission, we recorded NMDA-EPSCs in pairs of control and infected neurons expressing GFP-GluR1 mutants for 24-36 h. Neither GluR1(T887A) $(23.1 \pm 7.6$ vs. $19.8 \pm 4.4 \mathrm{pA}$, control vs. infected, $n=4)$ nor GluR1 $\Delta 7(23.5 \pm 3.0$ vs. $23.6 \pm 5.4 \mathrm{pA}$, control vs. infected, $n=6$ ) expression affect NMDA-EPSCs (Fig. 2D,E). We then recorded from individual infected neurons and, after monitoring stable baseline transmission, we induced LTP by pairing $3-\mathrm{Hz}$ Schaffer collateral stimulation with depolarization to $0 \mathrm{mV}$ for $180 \mathrm{sec}$. This is a stronger protocol than previously used (Hayashi et al. 2000; Barria and Malinow 2005), and we chose this to ensure that the absence of LTP with overexpression of the GluR1(T887A) mutant had not been an artifact of the weaker induction protocol. Following pairing, synaptic transmission in neurons expressing GluR1(wt) or GluR1 7 remained elevated, indicating that these constructs did not interfere with LTP induction or expression (Fig. 3A,C). Synaptic transmission in neurons expressing GluR1(T887A) decayed to baseline levels $\sim 40 \mathrm{~min}$ following pairing (Fig. 3B). This is consistent with the previously described block of LTP expression (Hayashi et al. 2000), although, in the earlier study, the block occurred within 20 min 
A

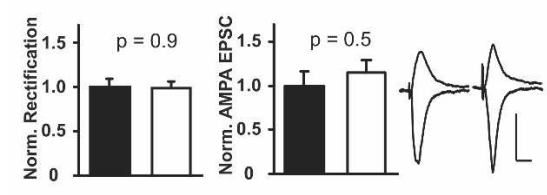

B GluR1(T887A)

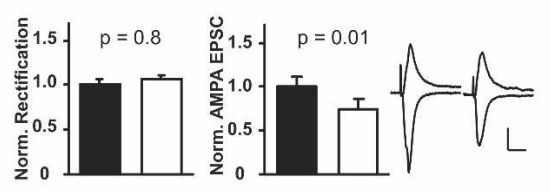

C

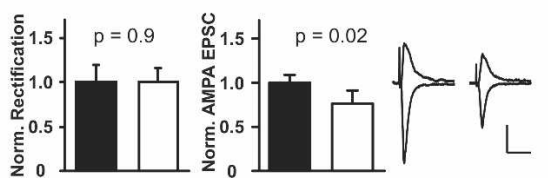

D GluR1(T887A)

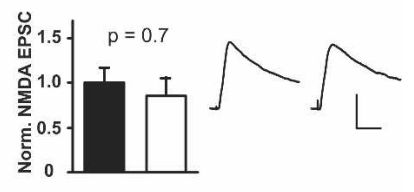

E GluR1 $\triangle 7$

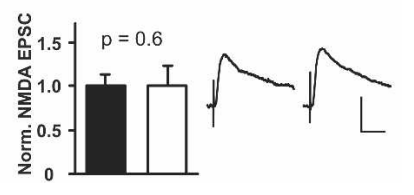

Figure 2. Wild-type or mutants of GluR1 were not delivered to synapses under basal conditions. $(A, B, C)$ Amplitudes and rectification of AMPA-mediated EPSCs recorded in pairs of CA1 neurons to assess if recombinant receptors were delivered to synapses. Amplitude and rectification values were normalized to that of control neurons. $(A)$ GluR1(wt) was not delivered to synapses. Rectification $(1 \pm 0.10$, control; $0.99 \pm 0.06$, infected, $n=10)$ and EPSC amplitude $(1 \pm 0.16$, control; $1.1 \overline{6} \pm 0.13$, infected, $n=12$ ) were not significantly different. (B) GluR1(T887A) was not delivered to synapses. Rectification was not changed ( $1 \pm 0.07$ vs. $1.06 \pm 0.03$, control vs. infected, $n=7)$. EPSC amplitude was decreased from $1 \pm 0.11$ to $0.73 \pm 0.11$ (control vs. infected, $n=15)$. (C) GluR1 $(\Delta 7)$ was not delivered to synapses. Rectification was not changed ( $1 \pm 0.19$ vs. $1 \pm 0.13$, control vs. infected, $n=9$ ). The EPSC amplitude was slightly decreased from $1 \pm 0.09$ to $0.77 \pm 0.14$ (control vs. infected, $n=15$ ). Current traces are averages of $>50$ individual EPSCs recorded at $-60 \mathrm{mV}$ (inward current) and $+40 \mathrm{mV}$ (outward current) in the presence of APV. Scale bars: $20 \mathrm{pA}, 20 \mathrm{msec} .(D, E)$ Expression of GluR1(T887A) or GluR1 $(\Delta 7)$ had no effect on NMDA-mediated EPSCs. NMDA-currents were measured as the late component of the compound EPSC at $+40 \mathrm{mV}$, and values were normalized to that of control neurons. (D) Expression of GluR1(T887A) did not alter NMDA-EPSCs which were $1 \pm 0.17$ in control and $0.86 \pm 0.20$ in infected neurons, $(n=4)$. (E) Expression of GluR1 $(\Delta 7)$ did not alter NMDA-EPSCs, which were $1 \pm 0.13$ in control and $1.0 \pm 0.23$ in infected neurons $(n=6)$. Traces are averages of 30-50 individual EPSCs. Scale bars: 20 pA, 40 msec. (n) Number of cell pairs recorded. $P$-values are shown for paired Wilcoxon tests.

after LTP induction. Multiple processes may contribute to the expression of LTP, and the time course and specific contribution of each mechanism may depend on the stimulation protocol. Thus, it is not surprising to see differences in the time course of LTP block using a stronger LTP-induction protocol. Importantly, we again find a significant difference between the GluR1(T887A) and the GluR1 $\Delta 7$ mutants. GluR1 $\Delta 7$ and GluR1(wt) allow LTP to occur, while GluR1(T887A) blocks LTP (Fig. 3D). In summary, GluR1(T887A), but not GluR1 $\Delta 7$, blocks LTP and tCamKIIinduced synaptic potentiation, two different forms of synaptic plasticity.

Our data indicate that GluR1(T887A) and GluR1 4 , although originally intended to create the same phenotypic mutation, have different effects on synaptic plasticity when compared in parallel in the same experimental system. These data reconcile the different results obtained by Hayashi et al. (2000) and Kim et al. (2005). How could these subtle mutations produce such different physiological effects? One possibility is that two proteins compete antagonistically for access to the cytoplasmic tail of GluR1, much like GRIP and PICK (Chung et al. 2000; Lu and Ziff 2005) or AP2 and NSF (Lee et al. 2002) compete to interact with regions in the cytoplasmic tail of GluR2. Therefore, destroying the PDZ-ligand domain by introducing a point mutation might shift the interaction toward one of the two competing proteins. Deleting the last seven amino acids, on the other hand, would prevent interactions with both competing proteins. Interestingly, experiments using a GluR1 mutant in which the last four amino acids were deleted (the PDZ ligand only) mimicked the GluR1(T887A) point mutation in a cell biological assay of receptor delivery (Passafaro et al. 2001). This suggests that a lost (and not a newly gained) interaction of GluR1 with a PDZ protein is responsible for the T887A phenotype.

Taken together, our results indicate that the opposite outcomes of the two previous studies (Hayashi et al. 2000; Kim et al. 2005) were not due to the experimental systems used (mouse knockin vs. virally infected hippocampal slice cultures), but are due to a biological difference in the GluR1 mutants. We conclude that the PDZ interaction at the GluR1 cytoplasmic tail is not required for synaptic plasticity, but plays a modulatory role. The molecular identity of these modulatory protein interactions is unknown, but, based on current literature, SAP97 is a prime candidate for the PDZ-protein interaction at the T887 site during synaptic GluR1 delivery (Leonard et al. 1998; Sans et al. 2001; Cai et al. 2002). Furthermore, our data suggest multiple and potentially antagonistic protein interactions in the extreme cytoplasmic tail of GluR1.

\section{Acknowledgments}

We thank N. Dawkins for expert technical assistance. This work was supported by grants from the DFG and Alzheimer's Association (to J.B.), the NINDS (NRSA to H.H.), and the NIH (to R.M.).

\section{References}

Barria, A. and Malinow, R. 2005. NMDA receptor subunit composition controls synaptic plasticity by regulating binding to CaMKII. Neuron 48: 289-301.

Bredt, D.S. and Nicoll, R.A. 2003. AMPA receptor trafficking at excitatory synapses. Neuron 40: 361-379.

Brown, T.C., Tran, I.C., Backos, D.S., and Esteban, J.A. 2005. NMDA receptor-dependent activation of the small GTPase Rab5 drives the removal of synaptic AMPA receptors during hippocampal LTD. Neuron 45: 81-94.

Cai, C., Coleman, S.K., Niemi, K., and Keinanen, K. 2002. Selective binding of synapse-associated protein 97 to GluR-A $\alpha$-amino-5-hydroxy-3-methyl-4-isoxazole propionate receptor subunit is determined by a novel sequence motif. J. Biol. Chem. 277: 31484-31490.

Chang, H.C. and Rongo, C. 2005. Cytosolic tail sequences and subunit interactions are critical for synaptic localization of glutamate receptors. J. Cell Sci. 118: 1945-1956.

Chung, H.J., Xia, J., Scannevin, R.H., Zhang, X., and Huganir, R.L. 2000. Phosphorylation of the AMPA receptor subunit GluR2 differentially regulates its interaction with PDZ domain-containing proteins. $J$. Neurosci. 20: 7258-7267.

Garner, C.C., Nash, J., and Huganir, R.L. 2000. PDZ domains in synapse assembly and signalling. Trends Cell Biol. 10: 274-280.

Hayashi, Y., Shi, S.H., Esteban, J.A., Piccini, A., Poncer, J.C., and Malinow, R. 2000. Driving AMPA receptors into synapses by LTP and CaMKII: Requirement for GluR1 and PDZ domain interaction. Science 287: 2262-2267.

Kim, E. and Sheng, M. 2004. PDZ domain proteins of synapses. Nat. Rev. Neurosci. 5: 771-781. 

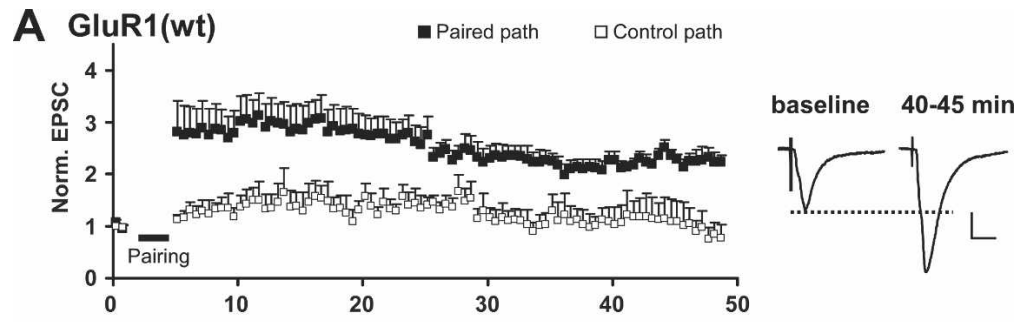

B GluR1(T887A)
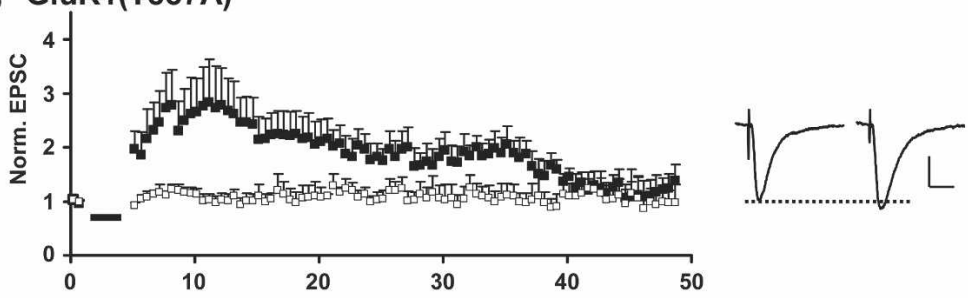

C GluR1 $\Delta 7$
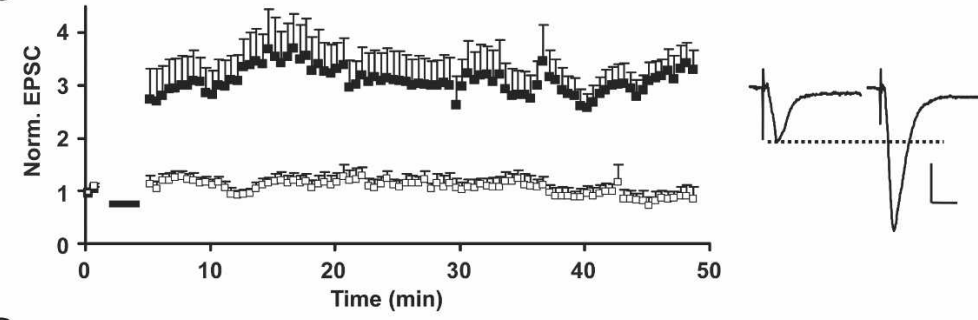

D

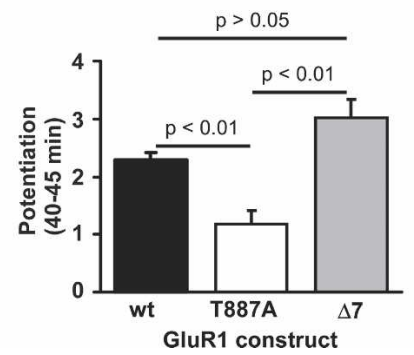

Figure 3. LTP was blocked by expression of GluR1(T887A), but not by expression of GluR1 $\Delta 7$. $(A, B, C)$ Time courses of changes in AMPA-mediated EPSCs following the induction of LTP recorded from CA1 pyramidal neurons expressing GFP-GluR1 constructs. LTP was induced by pairing $3-\mathrm{Hz}$ stimulation with postsynaptic depolarization to $0 \mathrm{mV}$ for $180 \mathrm{sec}$ (bars). The EPSC size was normalized to baseline levels. Control and paired pathways are shown. ( $A$ ) LTP was observed in neurons expressing GluR1(wt) $(n=7)$. (B) LTP was blocked in neurons expressing GluR1(T887A) $(n=7)$. (C) LTP was observed in neurons expressing GluR1 $\Delta 7(n=8)$. Traces (averages of 30 sweeps) show EPSCs recorded at $-60 \mathrm{mV}$ before (baseline) and $40-45 \mathrm{~min}$ after pairing. Scale bars: $20 \mathrm{pA}, 10 \mathrm{msec}$. (D) Comparison of LTP magnitude 40-45 min after pairing for all GluR1 constructs. Potentiation was $2.29 \pm 0.12$ $(n=7)$ for GluR1(wt), $1.17 \pm 0.23(n=7)$ for GluR1(T887A), and $3.03 \pm 0.31(n=8)$ for GluR1 $\Delta 7$ Levels of LTP were not significantly different in neurons expressing GluR1 (wt) and GluR1 $\Delta 7$. Potentiation for both these constructs differed from GluR1(T887A). (n) Number of cells. P-values are shown for Mann-Whitney test.

Kim, C.H., Takamiya, K., Petralia, R.S., Sattler, R., Yu, S., Zhou, W., Kalb, R., Wenthold, R., and Huganir, R. 2005. Persistent hippocampal CA1 LTP in mice lacking the C-terminal PDZ ligand of GluR1. Nat. Neurosci. 8: 985-987.

Lee, S.H., Liu, L., Wang, Y.T., and Sheng, M. 2002. Clathrin adaptor AP2 and NSF interact with overlapping sites of GluR2 and play distinct roles in AMPA receptor trafficking and hippocampal LTD. Neuron 36: $661-674$.

Leonard, A.S., Davare, M.A., Horne, M.C., Garner, C.C., and Hell, J.W. 1998. SAP97 is associated with the $\alpha$-amino-3-hydroxy-5-methylisoxazole-4propionic acid receptor GluR1 subunit. $J$. Biol. Chem. 273: 19518-19524.

Lu, W. and Ziff, E.B. 2005. PICK1 interacts with ABP/GRIP to regulate AMPA receptor trafficking. Neuron 47: 407-421.

Malinow, R. and Malenka, R.C. 2002. AMPA receptor trafficking and synaptic plasticity. Annu. Rev. Neurosci. 25: 103-126.

Passafaro, M., Piech, V., and Sheng, M. 2001. Subunit-specific temporal and spatial patterns of AMPA receptor exocytosis in hippocampal neurons. Nat. Neurosci. 4: 917-926.

Piccini, A. and Malinow, R. 2002. Critical postsynaptic density 95/disc large/zonula occludens- 1 interactions by glutamate receptor 1 (GluR1) and GluR2 required at different subcellular sites. J. Neurosci. 22: 5387-5392.

Poncer, J.C., Esteban, J.A., and Malinow, R. 2002. Multiple mechanisms for the potentiation of AMPA receptor-mediated transmission by $\alpha-\mathrm{Ca}^{2+} /$ calmodulin-dependent protein kinase II. J. Neurosci. 22: 4406-4411.

Rumpel, S., LeDoux, J., Zador, A., and Malinow, R. 2005. Postsynaptic receptor trafficking underlying a form of associative learning. Science 308: 83-88.

Sans, N., Racca, C., Petralia, R.S., Wang, Y.X., McCallum, J., and Wenthold, R.J. 2001. Synapse-associated protein 97 selectively associates with a subset of AMPA receptors early in their biosynthetic pathway. J. Neurosci. 21: 7506-7516.

Shi, S.H., Hayashi, Y., Petralia, R.S., Zaman, S.H., Wenthold, R.J., Svoboda, K., and Malinow, R. 1999. Rapid spine delivery and redistribution of AMPA receptors after synaptic NMDA receptor activation. Science 284: 1811-1816.

Shi, S., Hayashi, Y., Esteban, J.A., and Malinow, R. 2001. Subunit-specific rules governing AMPA receptor trafficking to synapses in hippocampal pyramidal neurons. Cell 105: 331-343.

Songyang, Z., Fanning, A.S., Fu, C., Xu, J., Marfatia, S.M., Chishti, A.H., Crompton, A., Chan, A.C., Anderson, J.M., and Cantley, L.C. 1997. Recognition of unique carboxyl-terminal motifs by distinct PDZ domains. Science 275: 73-77.

Stoppini, L., Buchs, P.A., and Muller, D. 1991. A simple method for organotypic cultures of nervous tissue. J. Neurosci. Methods 37: 173-182.

Takahashi, T., Svoboda, K., and Malinow, R. 2003. Experience strengthens transmission by driving AMPA receptors into synapses. Science 299: 1585-1588.

Zhu, J.J., Esteban, J.A., Hayashi, Y., and Malinow, R. 2000. Postnatal synaptic potentiation: Delivery of GluR4-containing AMPA receptors by spontaneous activity. Nat. Neurosci. 3: 1098-1106.

Zhu, Y., Pak, D., Qin, Y., McCormack, S.G., Kim, M.J., Baumgart, J.P., Velamoor, V., Auberson, Y.P., Osten, P., van Aelst, L., et al. 2005. Rap2-JNK removes synaptic AMPA receptors during depotentiation. Neuron 46: 905-916.

Received March 16, 2006; accepted in revised form June 13, 2006. 


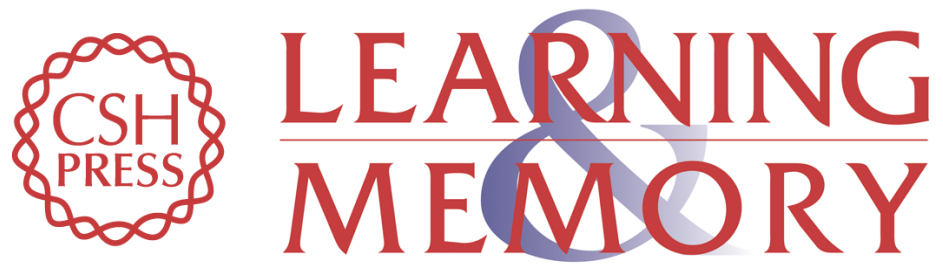

\section{Two mutations preventing PDZ-protein interactions of GluR1 have opposite effects on synaptic plasticity}

Jannic Boehm, Ingrid Ehrlich, Helen Hsieh, et al.

Learn. Mem. 2006, 13:

Access the most recent version at doi:10.1101//m.253506

References This article cites 26 articles, 12 of which can be accessed free at: http://learnmem.cshlp.org/content/13/5/562.full.html\#ref-list-1

License

Email Alerting Receive free email alerts when new articles cite this article - sign up in the box at the Service top right corner of the article or click here. 